\title{
Use of condensed silica fume for making high- strength, self-consolidating concrete
}

\author{
A.K.H. Kwan
}

\begin{abstract}
A high concrete strength can be achieved by lowering the water/binder ratio and a high workability by adding a higher dosage of superplasticizer. However, a high-performance concrete with both high strength and high workability cannot be produced by just these means because lowering the water/binder ratio leads to lower workability and there is a limit to the increase in workability that can be attained by adding superplasticizer. To produce a highstrength, high-workability concrete, the concrete strength needs to be increased without lowering the water/binder ratio. This can be done by adding condensed silica fume. In this study, a series of trial mixing aimed at developing highstrength, self-consolidating concrete (mean cube strength $>80 \mathrm{MPa}$ and needs no compaction for consolidation) was carried out. Several mixes suitable for making such high-performance concrete have been developed and it was found that the addition of condensed silica fume may, under favourable conditions, increase not only the strength but also the workability of the concrete mix. Based on the trial mix results, charts for the design of high-strength, high-workability concrete mixes made of the studied constituents are presented.
\end{abstract}

Key words: condensed silica fume, high-strength concrete, self-consolidating concrete.

Résumé : Un béton à haute résistance peut être obtenu en abaissant le rapport eau/liant, tandis qu'une haute fonctionalité s'aquiert par l'ajout d'une plus haute dose de superplastifiants. Pourtant, un béton à haute performance avec une haute résistance et une haute fonctionalité ne peut pas juste être produit par ces moyens parce que le fait d'abaisser le rapport eau/liant aboutit à une fonctionalité plus basse, et il y a une limite à l'augmentation dans la fonctionalité qui peut être atteinte en ajoutant un superplastifiant. Pour produire un béton à haute résistance et à haute fonctionalité, la résistance du béton doit être augmentée sans diminuer le rapport eau/liant. Cela peut être achevé en ajoutant de la fumée de silice condensée. Dans cette étude, une série de mélanges prototypes visant à développer du béton à haute résistance et autoconsolidant (résistance moyenne d'un cube $>80 \mathrm{MPa}$ et n'a pas besoin de compaction pour se consolider) a été effectuée. Plusieurs mélanges convenables pour faire un pareil béton à haute résistance ont été développé et il fut trouvé que l'addition de la fumée de silice condensée peut sous des conditions favorables augmenter non seulement la résistance mais aussi la fonctionalité du mélange de béton. Basé sur les résultats des mélange prototypes, des graphiques pour la conception de mélanges de béton à haute résistance et à haute fonctionalité, faites à partir des composantes étudiées sont présentés.

Mots clés: fumée de silice condensée, béton à haute résistance, béton autoconsolidant.

[Traduit par la Rédaction]

\section{Introduction}

High-strength concrete has been traditionally produced by lowering the water/cement ratio. This, however, reduces the workability of the concrete mix and renders the concrete mix more difficult to compact. That was why the earliest highstrength concretes were mostly 0-25 mm slump "laboratory concretes" (Parrott 1969). The workability can be restored to a more acceptable level by adding superplasticizer. A superplasticizer can be used in two ways, as shown in Fig. 1. First, it can be added to the concrete mix without changing the water/cement ratio to increase the workability. Second, for a given workability requirement, it can be used to reduce

Received February 2, 1999.

Revised manuscript accepted December 8, 1999.

A.K.H. Kwan. Department of Civil Engineering, The University of Hong Kong, Pokfulam Road, Hong Kong, China.

Written discussion of this article is welcomed and will be received by the Editor until December 31,2000 . the water demand and hence the water/cement ratio so as to increase the concrete strength.

But even with superplasticizer added, there is a practical limit to the highest strength and (or) workability that can be achieved. With the use of only a low water/cement ratio, a high cement content, and superplasticizer, the highest concrete cube strength that can be reached at normal field placeable workability (at least $50 \mathrm{~mm}$ slump) is only about $80 \mathrm{MPa}$ (Wolsiefer 1984). If higher workability is required, then the water/cement ratio must be increased and the concrete strength reduced. It is, therefore, not easy to produce a concrete that has both high strength and high workability using just cement and superplasticizer.

It was not until 1984 when field placeable concrete with a cube strength higher than $85 \mathrm{MPa}$ was first commercially produced (Wolsiefer 1984). This was made possible by adding condensed silica fume (CSF). At the same water/binder ratio (binder $=$ cement $+\mathrm{CSF}+$ other cementitious materials), CSF can increase the concrete strength by up to $30 \%$ or more. Hence, the use of CSF allows us to push the concrete strength upward without further reduction of the water/binder 
Fig. 1. Use of superplasticizer.

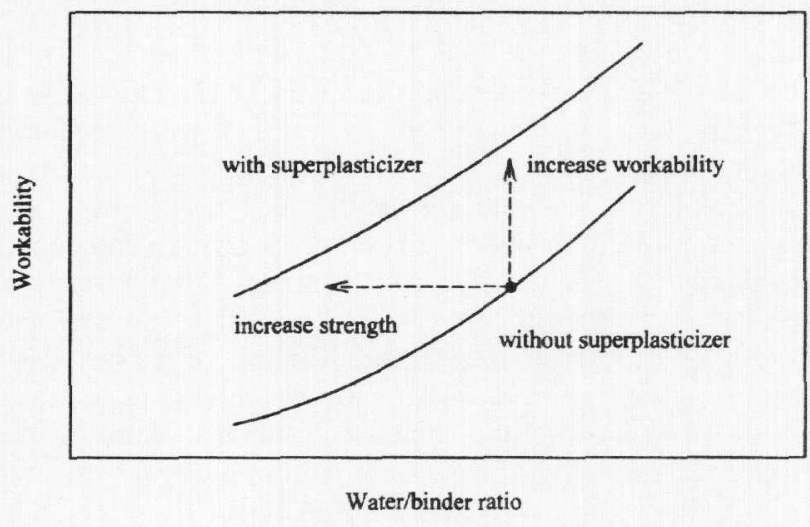

ratio. It also allows us to adopt a higher water/binder ratio for the same concrete strength to increase the workability (although the addition of CSF without changing the water/binder ratio could reduce the workability, the addition of CSF together with the use of a higher water/binder ratio for the same strength would increase the workability), as illustrated in Fig. 2. Therefore, like superplasticizer, CSF can be used to increase the concrete strength or the workability, or both.

Because of their high fines content, high-strength concrete mixes tend to be quite cohesive, sticky, and viscous. Experience with high-strength concrete has revealed that even at the same slump value, which is commonly taken as a measure of workability, a higher strength concrete mix is generally more difficult to compact. In other words, a higher strength concrete mix needs a higher slump for proper consolidation. With the increasingly common practice of designing concrete structures, especially tall concrete building structures, to contain congested steel reinforcement, it is inevitably desirable to have, for in situ construction, highstrength concretes that have not only high strength but also high workability.

In response to requests from the construction industry for high-strength, high-workability concretes, the author has recently conducted a series of laboratory tests aiming to develop high-strength concretes that are so workable that they are in effect self-consolidating. Basically, a self-consolidating concrete is one that has sufficient flowability to level under its own weight and needs no vibration or compaction for consolidation. However, this specification for self-consolidating concrete is rather vague. To be more precise, it is proposed to define a self-consolidating concrete as one that has an uncompacted strength of at least $95 \%$ of the fully compacted strength. It is also proposed that for a quick check on site, the self-consolidating concrete should be specified to have a slump of at least $200 \mathrm{~mm}$. The objective of the experimental program is thus to develop concrete mixes having the following properties:

(1) high strength, that is, characteristic 28-day cube strength $>60 \mathrm{MPa}$ or mean 28-day cube strength $>80 \mathrm{MPa}$ (a margin of $20 \mathrm{MPa}$ is allowed)

(2) high workability, that is, slump $>200 \mathrm{~mm}$

(3) low risk of incomplete consolidation, that is, 28-day strength of uncompacted cubes $>95 \%$ of corresponding strength of fully compacted cubes
Fig. 2. Use of condensed silica fume.

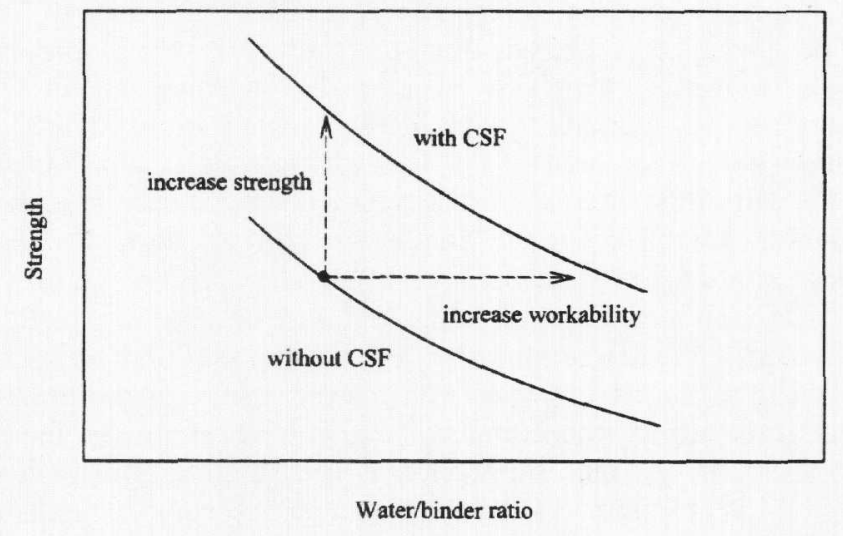

To produce such a high-performance concrete, it is foreseeable that both superplasticizer and CSF would be needed. Quite obviously, a very high dose of superplasticizer would be required; it is thus important to select one that can be used at high dosage without producing adverse side effects such as excessive retardation. If the limit is to be stretched to produce the highest strength and workability possible, the superplasticizer should be added up to the maximum dosage recommended by the manufacturer of the product. However, this may not necessarily yield the best overall results because the maximum dosage depends on the binders used and the maximum recommended dosage may not be the most economical. It is therefore suggested that after the preliminary mix design is worked out, further mix trials should be conducted to determine the saturation amount of superplasticizer (de Larrard et al. 1997) so as to provide a more rational basis for finalizing the superplasticizer dosage. On the other hand, it is not easy to determine the amount of CSF that should be added because a higher dosage of CSF does not necessarily yield a better concrete, as explained below.

In general, at a given water/binder ratio and a given slump, the concrete strength increases at a gradually decreasing rate as the CSF content increases and starts to decrease when the CSF content exceeds a certain optimum value. The optimum CSF content has been found to be dependent on the binder content, water/binder ratio, and dosage of superplasticizer (Yogendran et al. 1987; de Larrard 1989; Novokshchenov 1992) but is usually within 15-25\% of the total binder content. Due to the high price of CSF and the diminishing return of concrete strength at high CSF dosage, a CSF content lower than the optimum for maximum concrete strength may be more economical; because of the many variables involved, the amount of CSF to be added needs to be determined by trial mixing.

The effect of CSF on workability is quite difficult to predict because of its dependence on other mix parameters. With no superplasticizer added, it has been found that at a cement content of $100 \mathrm{~kg} \cdot \mathrm{m}^{-3}$ the water demand decreases as CSF is added, while at a cement content of more than $250 \mathrm{~kg} \cdot \mathrm{m}^{-3}$ the water demand increases when CSF is added (FIP Commission on Concrete 1988). With superplasticizer added, Domone and Soutsos (1995) have found that at water/binder ratios higher than 0.28 the addition of $10 \% \mathrm{CSF}$ as cement replacement increases the dosage of superplasticizer needed to maintain workability, but at wa- 
ter/binder ratios lower than 0.28 the same amount of CSF addition as cement replacement reduces the dosage of superplasticizer required. Hence, contrary to the common belief that the use of CSF at a fixed water/binder ratio always reduces workability and increases water demand due to the large surface area of the CSF particles, the addition of CSF can either increase or decrease the workability of the concrete mix. No general conclusion can yet be made and more studies are needed.

Although a trial and error process may be used to develop the required concrete mix, the time needed will be very long because of the necessity to wait for the results of the previous trials before proceeding to the next trial. Moreover, there is no certainty that the concrete mix arrived at by this method is optimum. Therefore, it should be better to conduct a systematic parametric study covering the expected ranges of mix parameters so that the combined effects of the mix parameters may be studied in detail during the course of mix development and a selection of mixes instead of just one mix may be developed for making high-strength, selfconsolidating concretes under different situations. In this study, the strategy of systematic parametric study is adopted. It will be seen that, using this strategy, it is possible to develop not only mixes for making high-strength, selfconsolidating concrete but also charts for designing concrete mixes to meet given high-strength and high-workability requirements.

\section{Experimental program}

\section{Proportioning of trial mixes}

The mix parameters that need to be considered are (1) paste volume, (2) CSF content, (3) whether other supplementary cementitious materials such as pulverized fuel ash (PFA) should be added, (4) water/binder (W/B) ratio, (5) type of superplasticizer to be used, and (6) dosage of superplasticizer.

A paste volume of $40 \%$ of the total volume of concrete was used because preliminary trials had indicated that it was difficult to achieve both high-strength and self-consolidating properties if a lower paste volume was used. This paste volume is the same as that of the commercially produced highstrength concrete developed by Wolsiefer (1984). Although this paste volume is somewhat higher than the maximum value of 35\% recommended by Mehta and Aitcin (1990), it is believed that, provided the cement content is limited to not more than $450 \mathrm{~kg} \cdot \mathrm{m}^{-3}$, the amount of heat of hydration generated should still be acceptable. Nevertheless, care should be taken to avoid thermal cracking when casting concretes with such high paste volume in massive concrete structures.

To study the effects of different CSF content, the CSF content was varied from 0 to $15 \%$ by weight of the total binder content. Preliminary tests had revealed that at a paste volume of $40 \%$ and a W/B ratio of 0.30 the concrete strength continued to increase with the CSF content even when the CSF content reached $20 \%$. In other words, the optimum CSF content for maximum concrete strength should be higher than $20 \%$ of total binder content. However, for economic reasons, it was decided to keep the CSF content at not more than $15 \%$ so that the resulting concrete mixes would not be too expensive to produce.

At a paste volume of $40 \%$, the total binder content would be about $650 \mathrm{~kg} \cdot \mathrm{m}^{-3}$, depending on the W/B ratio and the binder composition. If only cement and CSF were used, then even with $15 \% \mathrm{CSF}$ added, the resulting cement content (about $550 \mathrm{~kg} \cdot \mathrm{m}^{-3}$ ) would still be unacceptably high. It was, therefore, considered necessary to add some PFA as cement replacement to reduce the cement content. A fixed PFA content of $25 \%$ by weight of the total binder content was used because, from previous experience, the use of a higher PFA content would cause a significant reduction of concrete strength while the use of a lower PFA content would be less effective in reducing the cement content of the concrete mixes. It should be noted that the PFA and CSF were added in such a way that the paste volume was kept constant at $40 \%$.

Six W/B ratios ranging from 0.22 to 0.32 were used. These are common W/B ratios adopted for the production of high-strength concrete. Water/binder ratios outside this range were not considered because at lower or higher W/B ratios it would be difficult to meet both the workability and strength requirements.

Regarding the superplasticizer to be used, it should be one that can be used at relatively high dosage without producing adverse side effects. Several brands of superplasticizers were tried and evaluated. It was found that not all of them were suitable for use at dosage higher than $2 \%$ by dry weight of the total binder content because of the excessive retardation effect produced by some of them. After the evaluation, it was decided to use a naphthalene-based superplasticizer that, according to the manufacturer, was specially formulated for application at high dosage rate. It had been used at dosages up to $3 \%$ without showing significant adverse side effects during the product evaluation. As the manufacturer recommended a maximum dosage of $3 \%$, a fixed dosage of $3 \%$ was used in all the concrete mixes. Although this dosage appears high, even higher dosages of $4 \%$ and $5 \%$, respectively, have been applied by Sabir (1995) and Bayasi and Zhou (1993).

After the above considerations, it was decided that the experimental program should consist of a series of trial mixing of concrete mixes with paste volume fixed at $40 \%$, CSF contents of $0,5,10$, or $15 \%$, PFA content fixed at $25 \%$, W/B ratios of $0.22,0.24,0.26,0.28,0.30$, or 0.32 , and dosage of superplasticizer fixed at $3 \%$ by dry weight of the total binder content. A total of 24 concrete mixes were cast and tested. Details of the mix proportions are given in Table 1.

\section{Materials used}

The cement used was an ordinary portland cement that has been tested for compliance with the requirements of the British Standard BS12:1991 for portland cement of strength class $52.5 \mathrm{~N}$. It had a fineness of $355 \mathrm{~m}^{2} \cdot \mathrm{kg}^{-1}$ and is quite commonly used in the construction industry because of its relatively high fineness and high early strength. The PFA employed was a classified ash having a residue on $45 \mu \mathrm{m}$ sieve of $5.6 \%$ and a loss on ignition of $5.7 \%$. According to the supplier, the CSF used contained $94 \% \mathrm{SiO}_{2}$ and had a specific surface of $18000-20000 \mathrm{~m}^{2} \cdot \mathrm{kg}^{-1}$. The superplasticizer used, which was selected from several available 
products after an evaluation of their relative performance at dosages up to $3 \%$, was a naphthalene-based chemical admixture specially formulated for high dosage applications. It was added to the mixing water and well stirred until completely dissolved before addition to the concrete mixes.

Both the coarse and fine aggregates used were crushed volcanic rocks. The maximum size of the coarse aggregate was $10 \mathrm{~mm}$. A $10-\mathrm{mm}$ coarse aggregate was used instead of the more common $20-\mathrm{mm}$ coarse aggregate because the use of a smaller sized aggregate generally produces a higher concrete strength for a given binder content and a given slump (Mehta and Aitcin 1990). The coarse aggregate has been tested in accordance with the British Standard BS812:1990 to have a flakiness index of $28 \%$, an elongation index of $21 \%$, a crushing value of $16 \%$, and a $10 \%$ fines value of $300 \mathrm{kN}$. The fine aggregate has a fineness modulus of 3.2. Based on previous experience with the use of this volcanic aggregate, the fine to total aggregate ratio was fixed at 0.35 .

\section{Test procedures and conditions}

The trial mixes were prepared at room temperature of 15 $25^{\circ} \mathrm{C}$ and relative humidity of $50-70 \%$. All tests were conducted in accordance with the relevant British Standards except that the curing temperature was set at $27^{\circ} \mathrm{C}$. The workability of the concrete mixes was measured by the standard slump test. Cubes of $100-\mathrm{mm}$ size were used for the compressive strength tests. Twenty-four cubes were cast from each concrete mix. Half of the cubes were fully compacted by a poker vibrator and the remaining half were uncompacted. All the cubes were de-molded 1 day after casting and cured in a temperature-controlled lime-saturated water bath. The cubes were tested for compressive strength at ages of $7,14,28$, and 56 days. At each age, six cubes, three of which were fully compacted and three uncompacted, were crushed. The strength results of each set of three cubes were averaged to reduce experimental errors.

\section{Test results and discussions}

The test results of the 24 concrete mixes are summarized in Table 2. All the concrete mixes tested attained a 28-day cube strength of at least $60 \mathrm{MPa}$. A maximum concrete strength of $127 \mathrm{MPa}$ was achieved at a W/B ratio of 0.22 and a CSF content of $15 \%$. To better illustrate how the concrete strength varied with the W/B ratio and the CSF content, the strength results of the compacted cubes are plotted against the W/B ratio in Fig. 3 and against the CSF content in Fig. 4. Figure 3 reveals that at a fixed CSF content within 0 to $15 \%$, the concrete strength was roughly inversely proportional to the W/B ratio of the mix, whereas Fig. 4 shows very clearly that, within the range of mix parameters studied, the concrete strength increased with an increase in the CSF content. There was, however, an obvious sign of diminishing return when the CSF content was increased to beyond $10 \%$.

It is also seen from Table 2 that the increase in concrete strength as the W/B ratio decreased was obtained at the expense of reduced workability. This phenomenon is illustrated in Figs. 5 and 6 for concretes containing CSF contents of 5 and $15 \%$, respectively. Since both high strength and high workability are desirable properties, a compromise between
Table 1. Mix proportions of the 24 concrete mixes tested.

\begin{tabular}{|c|c|c|c|c|c|c|c|}
\hline \multirow{2}{*}{$\begin{array}{l}\text { Mix } \\
\text { no. }\end{array}$} & \multirow{2}{*}{$\begin{array}{l}\mathrm{W} / \mathrm{B} \\
\text { ratio }\end{array}$} & \multirow{2}{*}{$\begin{array}{l}\text { PFA } \\
(\%)\end{array}$} & \multirow{2}{*}{$\begin{array}{l}\text { CSF } \\
(\%)\end{array}$} & \multicolumn{4}{|c|}{$\begin{array}{l}\text { Mass of material per cubic metre } \\
\text { of concrete }(\mathrm{kg})\end{array}$} \\
\hline & & & & Cement & PFA & CSF & Water \\
\hline 1 & 0.22 & 25 & 0 & 514 & 171 & 0 & 151 \\
\hline 2 & & & 5 & 471 & 168 & 34 & 148 \\
\hline 3 & & & 10 & 430 & 165 & 66 & 145 \\
\hline 4 & & & 15 & 391 & 163 & 98 & 143 \\
\hline 5 & 0.24 & 25 & 0 & 497 & 166 & 0 & 159 \\
\hline 6 & & & 5 & 456 & 163 & 33 & 156 \\
\hline 7 & & & 10 & 416 & 160 & 64 & 154 \\
\hline 8 & & & 15 & 378 & 158 & 95 & 151 \\
\hline 9 & 0.26 & 25 & 0 & 481 & 160 & 0 & 167 \\
\hline 10 & & & 5 & 441 & 158 & 32 & 164 \\
\hline 11 & & & 10 & 403 & 155 & 62 & 161 \\
\hline 12 & & & 15 & 367 & 153 & 92 & 159 \\
\hline 13 & 0.28 & 25 & 0 & 466 & 155 & 0 & 174 \\
\hline 14 & & & 5 & 428 & 153 & 31 & 171 \\
\hline 15 & & & 10 & 391 & 151 & 60 & 169 \\
\hline 16 & & & 15 & 356 & 148 & 90 & 166 \\
\hline 17 & 0.3 & 25 & 0 & 452 & 151 & 0 & 181 \\
\hline 18 & & & 5 & 415 & 148 & 30 & 178 \\
\hline 19 & & & 10 & 380 & 146 & 58 & 175 \\
\hline 20 & & & 15 & 346 & 144 & 86 & 173 \\
\hline 21 & 0.32 & 25 & 0 & 439 & 146 & 0 & 187 \\
\hline 22 & & & 5 & 403 & 144 & 29 & 184 \\
\hline 23 & & & 10 & 369 & 142 & 57 & 182 \\
\hline 24 & & & 15 & 336 & 140 & 84 & 179 \\
\hline
\end{tabular}

Notes: (1) All mixes contained $3.0 \%$ by mass of total binder content of superplasticizer. (2) The water contents listed above are based on saturated surface dry aggregate and do not include the water added for compensating aggregate absorption. However, the water contained in the superplasticizer is included.

strength and workability is needed, and the W/B ratio to be adopted should be based on both considerations.

The workability results in Table 2 reveal that the slump varied with both the W/B ratio and the CSF content. Of particular interest is the effect of CSF content. Figure 7 shows graphically how the slump varied with the CSF content at different $\mathrm{W} / \mathrm{B}$ ratios. It is seen that at relatively high W/B ratios of 0.32 and 0.30 , the slump changed only slightly with the CSF content, being marginally higher as the CSF content was increased from 0 to $15 \%$. As the W/B ratio was reduced from 0.30 , the effect of CSF became more and more significant. At a W/B ratio of 0.28 , the effect of CSF was already so substantial that the slump increased from 100 to $235 \mathrm{~mm}$ when the CSF content was increased from 0 to $15 \%$. For very dry mixes with $\mathrm{W} / \mathrm{B}$ ratios ranging from 0.26 to 0.22 , the effect of CSF on workability may be described as very pronounced. Without CSF these concrete mixes had slump values of only $10-30 \mathrm{~mm}$. After addition of a CSF content of $15 \%$, their slump values increased markedly to around $130-165 \mathrm{~mm}$.

The above observed effect of CSF on workability may be explained by the filling effect of the ultrafine CSF particles. The CSF particles, being of size generally less than $1 \mu \mathrm{m}$, are many times finer than the cement and PFA particles. They can fill the gaps between the cement and PFA particles and thus reduce the void content in the bulk volume of the 
Table 2. Results of the 24 concrete mixes tested.

\begin{tabular}{|c|c|c|c|c|c|c|c|}
\hline \multirow[b]{2}{*}{$\begin{array}{l}\text { Mix } \\
\text { no. }\end{array}$} & \multirow[b]{2}{*}{$\begin{array}{l}\text { W/B } \\
\text { ratio }\end{array}$} & \multirow[b]{2}{*}{$\begin{array}{l}\text { PFA } \\
(\%)\end{array}$} & \multirow[b]{2}{*}{$\begin{array}{l}\text { CSF } \\
(\%)\end{array}$} & \multirow[b]{2}{*}{$\begin{array}{l}\text { Slump } \\
(\mathrm{mm})\end{array}$} & \multicolumn{3}{|c|}{ 28-day cube strength (MPa) } \\
\hline & & & & & $\begin{array}{l}\text { Un- } \\
\text { compacted }\end{array}$ & $\begin{array}{l}\text { Fully } \\
\text { compacted }\end{array}$ & $\begin{array}{l}\text { Strength } \\
\text { ratio }^{a}\end{array}$ \\
\hline 1 & 0.22 & 25 & 0 & 10 & 75.6 & 97.1 & 0.78 \\
\hline 2 & & & 5 & 75 & 105.8 & 110.9 & 0.95 \\
\hline 3 & & & 10 & 105 & 95.2 & 122.7 & 0.78 \\
\hline 4 & & & 15 & 130 & 112.6 & 127.2 & 0.89 \\
\hline 5 & 0.24 & 25 & 0 & 15 & 50.8 & 93.3 & 0.54 \\
\hline 6 & & & 5 & 100 & 91.2 & 99.3 & 0.92 \\
\hline 7 & & & 10 & 150 & 107.3 & 113.4 & 0.95 \\
\hline 8 & & & 15 & 160 & 113.7 & 122 & 0.93 \\
\hline 9 & 0.26 & 25 & 0 & 30 & 66.8 & 79.7 & 0.84 \\
\hline 10 & & & 5 & 120 & 81.1 & 84.8 & 0.96 \\
\hline 11 & & & 10 & 150 & 86.0 & 98.1 & 0.88 \\
\hline 12 & & & 15 & 165 & 90.7 & 104.5 & 0.87 \\
\hline 13 & 0.28 & 25 & 0 & 100 & 69.7 & 74.3 & 0.94 \\
\hline 14 & & & 5 & 140 & 76.3 & 82.4 & 0.93 \\
\hline 15 & & & 10 & 200 & 84.0 & 91.3 & 0.92 \\
\hline 16 & & & 15 & 235 & 91.2 & 96.6 & 0.94 \\
\hline 17 & 0.3 & 25 & 0 & 205 & 65.4 & 66.9 & 0.98 \\
\hline 18 & & & 5 & 230 & 72.9 & 76.9 & 0.95 \\
\hline 19 & & & 10 & 235 & 85.5 & 87.2 & 0.98 \\
\hline 20 & & & 15 & 250 & 89.3 & 92.4 & 0.97 \\
\hline 21 & 0.32 & 25 & 0 & 235 & 60.3 & 62.0 & 0.97 \\
\hline 22 & & & 5 & 235 & 68.1 & 70.5 & 0.97 \\
\hline 23 & & & 10 & 240 & 81.1 & 83.1 & 0.98 \\
\hline 24 & & & 15 & 260 & 89.0 & 89.2 & 1.00 \\
\hline
\end{tabular}

the fully compacted cubes.

Fig. 3. Variation of concrete strength with W/B ratio.

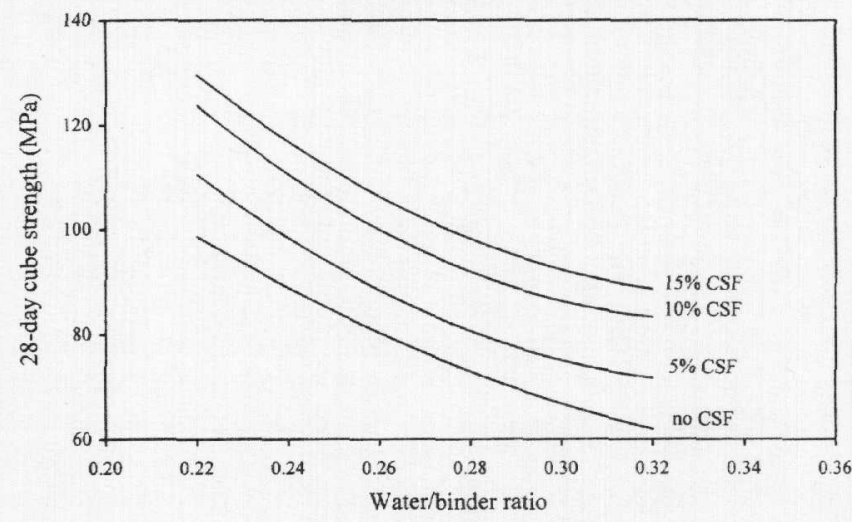

binder. When water is added to the binder paste, the water must first fill up the voids in the bulk volume of the binder, and it is the water in excess of the amount needed to fill up the voids that lubricates the paste to produce workability. Without CSF, the void content in the bulk volume of the binder is relatively high and a larger amount of water is needed to fill up the voids, leaving behind a smaller amount of water to lubricate the paste. With CSF filling part of the gaps between the larger cement and PFA particles, the amount of water needed to fill up the voids is reduced, and as a result more water is freed to lubricate the paste. At high W/B ratio, the amount of water in excess of that needed to fill up the voids in the bulk volume of binder is relatively
Fig. 4. Variation of concrete strength with CSF content.

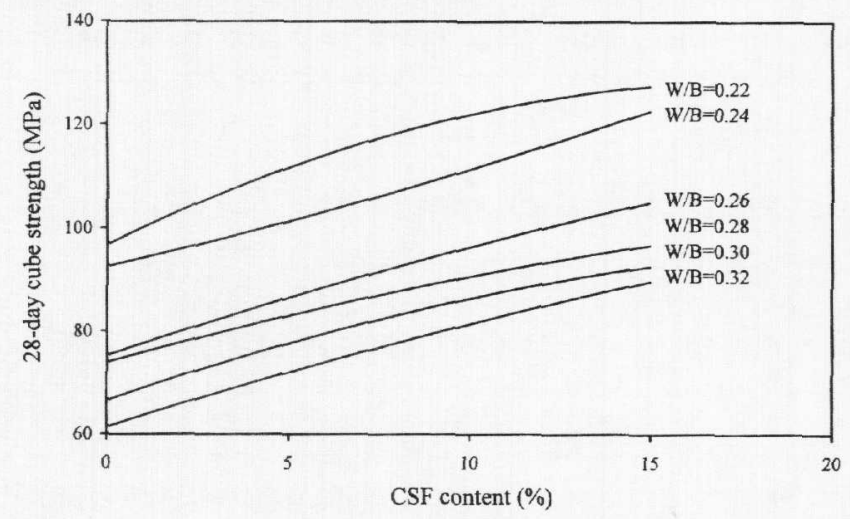

high, and thus the filling effect of CSF is less apparent. However, at low W/B ratio, the water content is relatively low, and thus the amount of water freed by the filling effect of CSF becomes more significant.

To see whether placing of the concrete mixes without compaction would adversely affect their strength, the strength ratio, defined as the ratio of the average strength of the uncompacted cubes to that of the fully compacted cubes, of each concrete mix tested is calculated and listed in the last column of Table 2 . The results reveal that the strength ratio is dependent mainly on the slump of the concrete mix. A plot of the strength ratio against the slump is shown in Fig. 8. The strength ratio results are quite scattered when the 
Fig. 5. Effect of W/B ratio on strength and workability at a CSF content of $5 \%$.

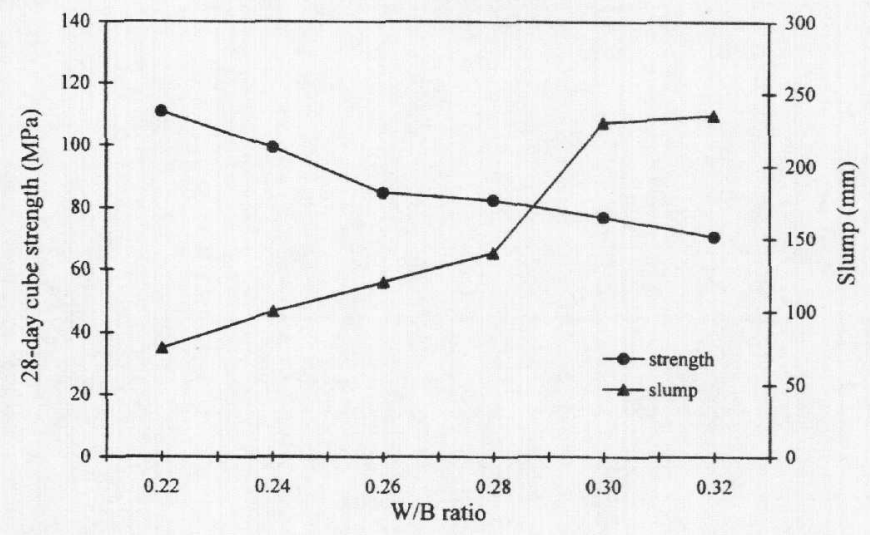

Fig. 6. Effect of W/B ratio on strength and workability at a CSF content of $15 \%$.

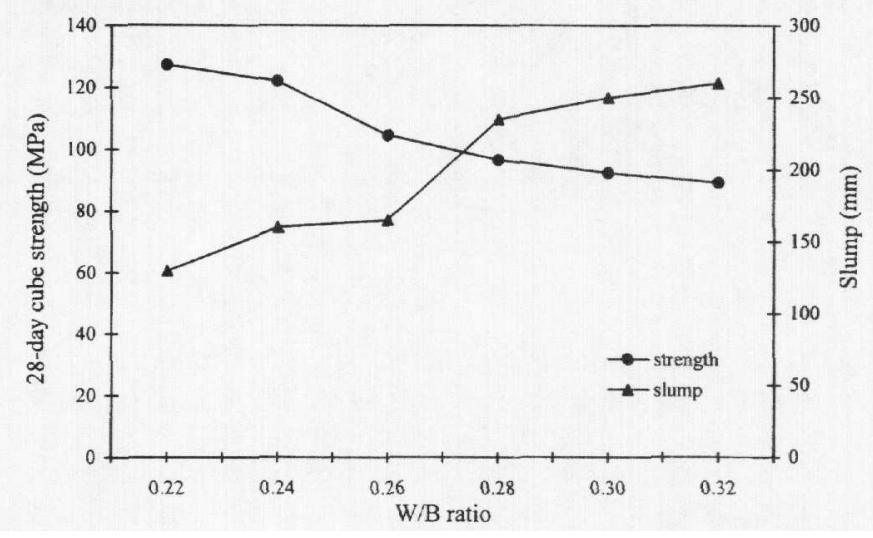

slump is low but the fluctuation becomes smaller when the slump is greater than $150 \mathrm{~mm}$. To show the trend of variation, a best-fit line is drawn in the diagram. The best-fit line indicates that within the range of mix parameters studied the slump required to achieve a strength ratio of 0.95 (minimum for a self-consolidating concrete) is about $200 \mathrm{~mm}$. This required slump of $200 \mathrm{~mm}$ may be used as a quick check on site. However, it should be taken as a necessary rather than a sufficient condition because concrete with a lower paste volume or made of materials different from those used in this study may require a greater slump to become selfconsolidating.

From the concrete mixes tested, those which satisfy the criteria for high-strength, self-consolidating concrete are selected and listed together with their strength and workability results in Table 3 . All the selected mixes have cement contents lower than $380 \mathrm{~kg} \cdot \mathrm{m}^{-3}$. However, they all contain a fairly high CSF content of $10-15 \%$. Among them, mix 16 has the highest mean strength of $96.6 \mathrm{MPa}$ and mix 20 has the second highest mean strength of 92.4 MPa. These two mixes may be used for the production of self-consolidating Grade 75 and Grade 70 concretes, respectively. Among the remaining mixes, mix 19 and mix 24 may be considered for making self-consolidating Grade 65 concrete, whereas mix 20 is suitable for self-consolidating Grade 60 concrete.
Fig. 7. Effect of CSF content on workability at different W/B ratios.

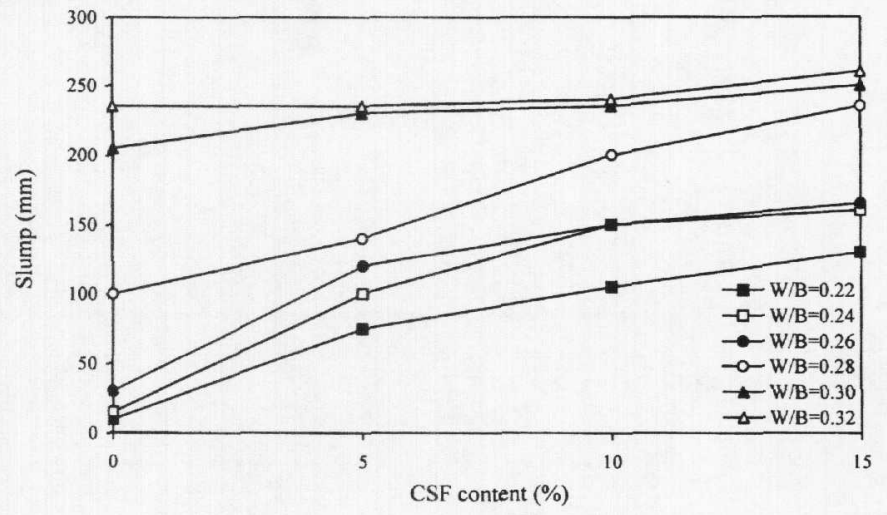

Fig. 8. Variation of strength ratio with slump.

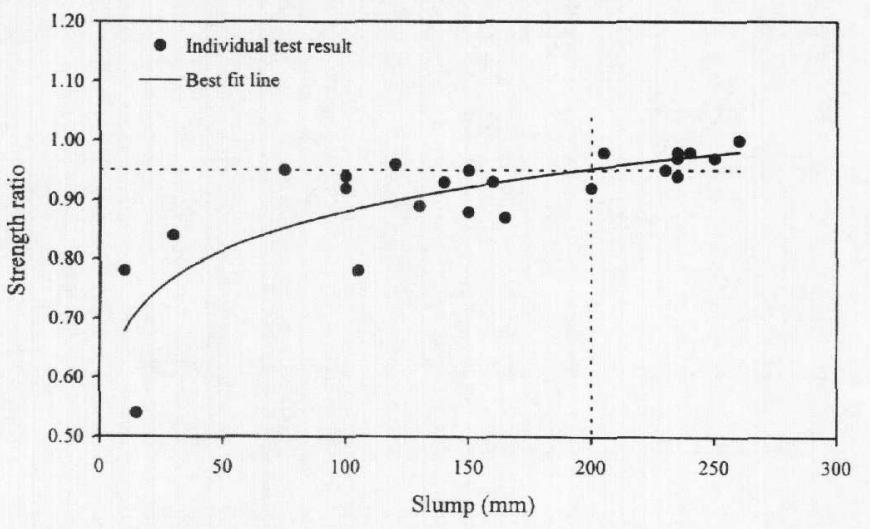

\section{Charts for mix design}

As previously mentioned, both the strength and workability requirements need to be considered when designing the mix parameters of a high-strength, highworkability concrete. For mix design purposes, the workability results of the concrete mixes tested are plotted against the strength results in Figs. 9 and 10 for fixed CSF contents and fixed $W / B$ ratios, respectively. It can be seen from Fig. 9 that the addition of CSF improves both the strength and workability of the concrete. The amount of CSF required can be determined from the figure by plotting the point with the specified strength as $x$-coordinate and the specified workability as $y$-coordinate on the graph and reading out the corresponding value of CSF content. From Fig. 10, it can be seen that the W/B ratio has opposite effects on the strength and the workability; as the $\mathrm{W} / \mathrm{B}$ ratio is varied, either the strength is increased at the expense of workability or the workability is increased at the expense of strength. A suitable W/B ratio for specified strength and workability can be determined from the figure by plotting the point with the specified strength and workability as $x$ and $y$-coordinates on the graph and reading the corresponding $\mathrm{W} / \mathrm{B}$ ratio.

Figures 9 and 10 are combined to form Fig. 11, which may then be used as a chart for the design of high-strength, high-workability concrete mixes. For instance, if a high- 
Table 3. Selected mixes for production of high-strength self-consolidating concrete.

\begin{tabular}{|c|c|c|c|c|c|c|c|}
\hline \multirow[b]{2}{*}{$\begin{array}{l}\text { Mix } \\
\text { no. }\end{array}$} & \multirow[b]{2}{*}{$\begin{array}{l}\mathrm{W} / \mathrm{B} \\
\text { ratio }\end{array}$} & \multirow[b]{2}{*}{$\begin{array}{l}\text { PFA } \\
(\%)\end{array}$} & \multirow[b]{2}{*}{$\begin{array}{l}\text { CSF } \\
(\%)\end{array}$} & \multirow{2}{*}{$\begin{array}{l}\text { Cement } \\
\text { content } \\
\left(\mathrm{kg} \cdot \mathrm{m}^{-3}\right)\end{array}$} & \multirow[b]{2}{*}{$\begin{array}{l}\text { Slump } \\
(\mathrm{mm})\end{array}$} & \multicolumn{2}{|c|}{ 28-day cube strength $(\mathrm{MPa})$} \\
\hline & & & & & & $\begin{array}{l}\text { Un- } \\
\text { compacted }\end{array}$ & $\begin{array}{l}\text { Fully } \\
\text { compacted }\end{array}$ \\
\hline 16 & 0.28 & 25 & 15 & 356 & 235 & 91.2 & 96.6 \\
\hline 19 & 0.30 & 25 & 10 & 380 & 235 & 85.5 & 87.2 \\
\hline 20 & 0.30 & 25 & 15 & 346 & 250 & 89.3 & 92.4 \\
\hline 23 & 0.32 & 25 & 10 & 369 & 240 & 81.1 & 83.1 \\
\hline 24 & 0.32 & 25 & 15 & 336 & 260 & 89.0 & 89.2 \\
\hline
\end{tabular}

Fig. 9. Variation of workability with strength at fixed CSF contents.

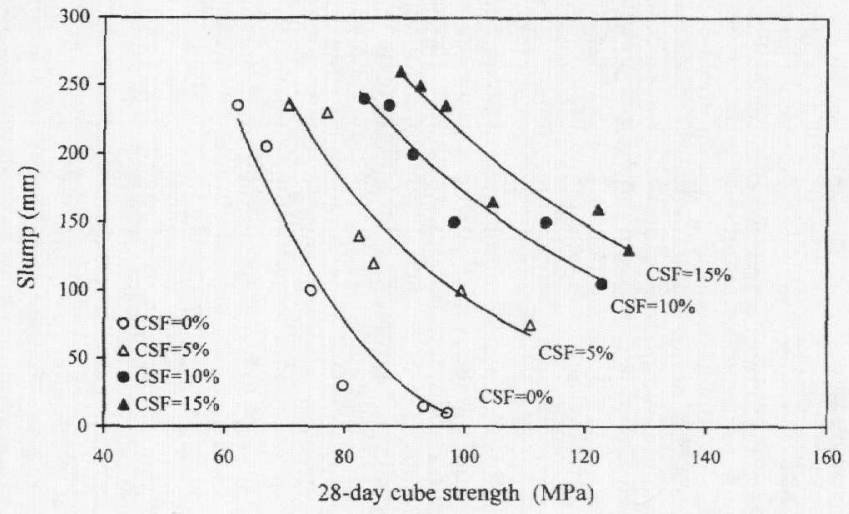

Fig. 10. Variation of workability with strength at fixed W/B ratios.

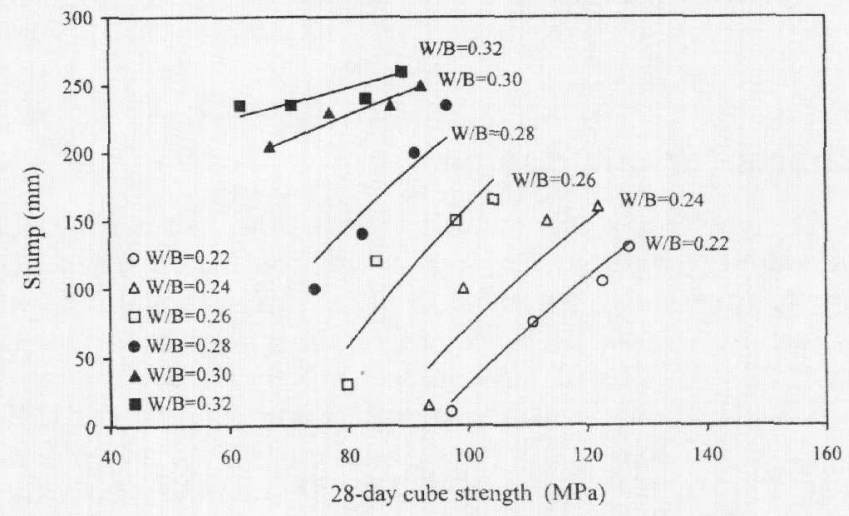

strength, high-workability concrete with a target mean strength of $80 \mathrm{MPa}$ and a slump of $200 \mathrm{~mm}$ is to be designed, the W/B ratio and CSF content can be determined from the figure by plotting the point with coordinates $(80$, 200 ) on the chart and reading the corresponding values of W/B ratio and CSF content as 0.30 and $7 \%$, respectively.

\section{Conclusions}

A series of trial mixing aiming to develop high-strength, self-consolidating concretes has been carried out. In total 24 concrete mixes with a fixed paste volume of $40 \%$, CSF content varying from 0 to $15 \%$, fixed PFA content of $25 \%$, W/B ratio ranging from 0.22 to 0.32 , and a fixed superplasticizer dosage of $3 \%$ have been cast and tested. A maximum workability of $260 \mathrm{~mm}$ has been achieved at a 28 -day com-
Fig. 11. Chart for mix design of high-strength, high-workability concrete.

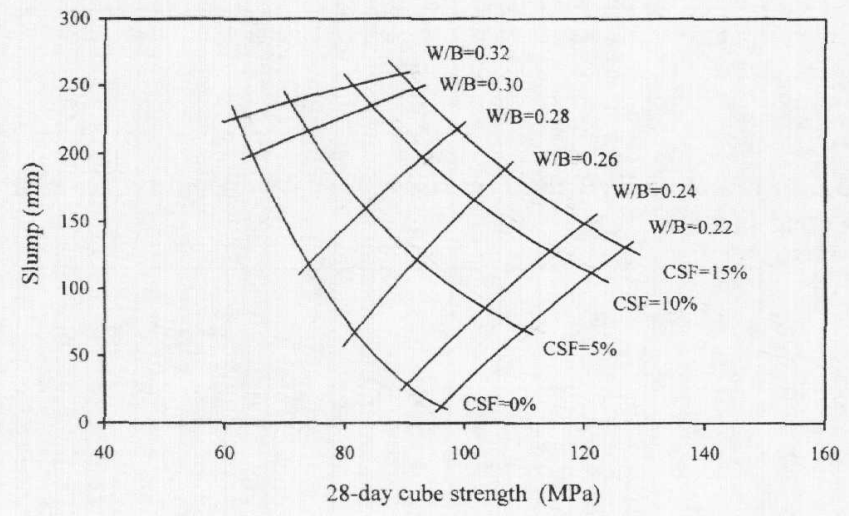

pacted cube strength of $89.2 \mathrm{MPa}$, whereas a maximum 28day compacted cube strength of $127.2 \mathrm{MPa}$ has been obtained at a workability of $130-\mathrm{mm}$ slump.

From the trial mixes tested, mixes that satisfy the criteria for high-strength, self-consolidating concrete are selected. Their mix proportions and corresponding strength and workability results are listed in Table 3 . They all have cement contents lower than $380 \mathrm{~kg} \cdot \mathrm{m}^{-3}$ but CSF contents of at least $10 \%$. It appears therefore that, as has been pointed out by others (de Larrard et al. 1996), CSF is indispensable for making high-strength, self-consolidating concretes. Among the selected mixes, some may be used for the production of self-consolidating Grade $70-75$ concrete.

The effects of W/B ratio and CSF content on concrete strength and workability have been studied by comparing the results of the different trial mixes. As expected, a lower W/B ratio leads to a higher strength but lower workability and vice versa. However, the effect of CSF is more pronounced. Within the range of mix parameters studied (paste volume of $40 \%$ and $\mathrm{W} / \mathrm{B}$ ratio less than or equal to 0.32 ), the addition of CSF increases not only the strength but also the workability of the concrete. An explanation, which attributes this phenomenon to the filling effect of the ultrafine CSF particles, has been given.

Based on the experimental data obtained, a design chart for the mix proportioning of high-strength, high-workability concrete is produced. Although this chart is applicable only to concrete mixes made of the materials used in this study, similar charts for concrete mixes made of other materials may be developed using the same methodology. The chart also helps to explain qualitatively the role of CSF in superplasticized concrete. 


\section{Acknowledgments}

The financial support of the Croucher Foundation of Hong Kong for the research work presented herein is gratefully acknowledged.

\section{References}

Bayasi, Z., and Zhou J. 1993. Properties of silica fume concrete and mortar. ACI Materials Journal, 90(4): 349-356.

Domone, P.L., and Soutsos, M.N. 1995. Properties of high-strength concrete mixes containing PFA and GGBS. Magazine of Concrete Research, 47(173): 355-367.

FIP Commission on Concrete. 1988. FIP state of the art report: condensed silica fume in concrete. Thomas Telford Ltd. London, England.

de Larrard, F. 1989. Ultrafine particles for the making of very high strength concrete. Cement and Concrete Research, 19: 161-172.

de Larrard, F., Gillet, G., and Canitrot, B. 1996. Preliminary HPC mix design for the "Gand Viaduc de Millau": an example of the LCPC approach. Proceedings of the Fourth International Symposium on Utilization of High Strength/High Performance Concrete, Paris, 1996, 3: 1323-1331. de Larrard, F., Bosc, F., Catherine, C., and de Florenne, F. 1997. The AFREM method for the mix design of HPC. Materials and Structures, 30(201): 439-446.

Mehta, P.K., and Aitcin, P.C. 1990. Microstructural basis of selection of materials and mix proportions for high strength concrete. Proceedings of the Second International Symposium on Utilization of High Strength Concrete, California, 1990, American Concrete Institute, Special Publication SP-121, 265-286.

Novokshchenov, V. 1992. Factors controlling the compressive strength of silica fume concrete in the range 100-150 MPa. Magazine of Concrete Research, 44(158): 53-61.

Parrott, L.J. 1969. The selection of constituents and proportions for producing workable concrete with a compressive cube strength of 80 to $110 \mathrm{~N} / \mathrm{mm}^{2}$. Technical Report TRA416, Cement and Concrete Association, London, England.

Sabir B.B. 1995. High-strength condensed silica fume concrete. Magazine of Concrete Research. 47(172): 219-226.

Wolsiefer, J. 1984. Ultra high-strength field placeable concrete with silica fume admixture. Concrete International: Design and Construction, 6(4): 25-31.

Yogendran, V., Langan, B.W., Haque, M.N., and Ward, M.A. 1987. Silica fume in high-strength concrete. ACI Materials Journal, 84(2): 124-129. 